\title{
Incidence of Non-Traumatic Subconjunctival Hemorrhage in an Indian Rural Population
}

This article was published in the following Dove Press journal:

Clinical Ophthalmology

\author{
Rajesh Subhash Joshi (iD) \\ Rahul Ramchandra Bandgar (D) ${ }^{2}$ \\ 'Department of Ophthalmology, \\ Government Medical College, Nagpur \\ 4400 12, Maharashtra, India; ${ }^{2}$ Department \\ of Ophthalmology, Shri Vasantrao Naik \\ Government Medical College, Yavatmal \\ 45I000I, Maharashtra, India
}

Purpose: To determine the incidence of non-traumatic subconjunctival hemorrhage (NTSH) in Indian rural population and analyze the associated risk factors.

Methods: The study included patients diagnosed having subconjunctival hemorrhage (SCH) who attended the out-patient department (OPD) of ophthalmology. Demographic characteristics of subjects included age, gender, medical and ocular history, and location of hemorrhage.

Results: The incidence rate of NTSH in this study was 3.07 per 1000 patients per year attending OPD. The men to women ratio for NTSH was 1.26 (95\% CI). The commonest site of presentation was nasal side $(n=36,51.4 \%)$. Right eye $(n=37,54.3 \%)$ was affected more than the left eye $(n=28,40 \%)$. The analysis showed 24 patients $(34.3 \%)$ did not have any etiological factor attributable to $\mathrm{SCH}$. Conjunctivochalasis $(\mathrm{CCH})$ was associated in 15 patients $(21.4 \%)$. An antiplatelet agent was associated with $\mathrm{SCH}$ in 7 patients $(10 \%)$. Other factors associated with SCH were hypertension, leukemia, and anemia $(n=6,8.6 \%)$.

Conclusion: This study indicates that NTSH occurs in 3 out of 1000 individuals per year in the rural population presenting to the OPD. Nasal conjunctiva was commonly involved. $\mathrm{CCH}$ was associated with 15 patients. Use of antiplatelet agents, hypertension and blood disorders are associated with the risk of NTSH. Patients presenting for the first time with NTSH should be screened for systemic etiological factors.

Keywords: subconjunctival hemorrhage, red eye, antiplatelet agents, conjunctivochalasis, hypertension

\section{Introduction}

Subconjunctival hemorrhage $(\mathrm{SCH})$ is a benign condition of eyes characterized by the collection of blood in the subconjunctival space (Figure 1). It is commonly associated with acute redness of eyes and is painless without any signs of acute inflammation of conjunctiva. Red eye is of great concern to many patients for which they may seek medical advice. However, this condition does not require any treatment and subsides within 2-3 weeks.

Broadly, $\mathrm{SCH}$ is classified into traumatic and non-traumatic. Local trauma is the most common cause of SCH. Spontaneous rupture of subconjunctival vessels leads to non-traumatic subconjunctival hemorrhage (NTSH). Other non-traumatic causes include patients on anticoagulant therapy, systemic hypertension, diabetes mellitus, and coagulopathies. However, a majority of these causes are idiopathic in nature.

In a large population-based survey by $\mathrm{Hu}$ et al on NTSH, the mean annual incidence quoted was 65 per 10,000 people. ${ }^{1}$ A literature search (10/10/2017) on MEDLINE revealed that the incidence of NTSH is not available for the Indian
Correspondence: Rajesh Subhash Joshi Government Medical College, Nagpur 4400I2, India

Email jrajesh5@rediffmail.com 


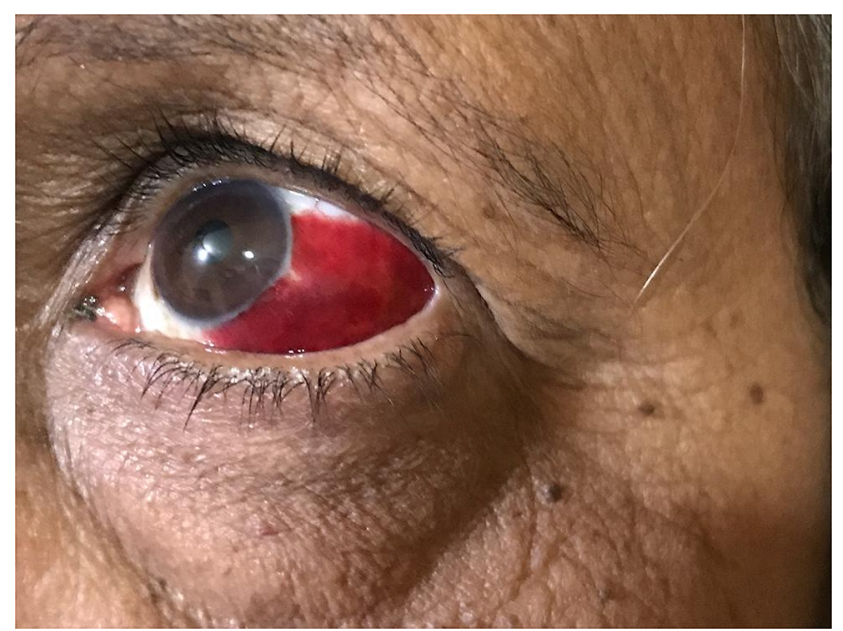

Figure I Showing subconjunctival hemorrhage.

population. Therefore, we designed this study to determine the incidence of NTSH in the Indian rural population.

\section{Methods}

The present study was a prospective, observational and noninterventional study conducted in a tertiary eye care center in a rural area from January-December 2016. Institutional review board (IRB) of Shri Vasantrao Naik Government Medical College and Hospital Yavatmal, Maharashtra, India approved the study. The study was conducted in adherence with the tenets of the Declaration of Helsinki. Consecutive patients with NTSH attending out-patient department (OPD) of our center were included in the study. Patients with SCH due to trauma to eye or brain and those with repeat $\mathrm{SCH}$ were excluded from the study.

Verbal informed consent as approved by the institutional review board of Shri Vasantrao Naik Government Medical College and Hospital, Yavatmal, Maharashtra, India was obtained from each participant for the examination. The demographic profile of patients included age, gender, ocular history to the onset of hemorrhage, presence of diabetes, hypertension, bleeding disorders, medications (like aspirin or any other blood thinners), eye rubbing, and lifting of heavy objects.

Ocular examination included slit lamp and dilated fundus examination. Patients were referred to a general physician to determine the etiological factors. Data were entered into an Excel sheet for further evaluation.

\section{Statistical Analysis}

Data were analyzed in MS EXCEL and EPI INFO Software 7.0. As the data were categorical by nature, the
Chi-Square test was used. Statistical difference was tested for $\mathrm{p}$ value $<0.05$ at $95 \%$ confidence interval.

\section{Results}

A total of 22,931 patients attended the ophthalmology OPD during the study period. After excluding 157 cases of traumatic SCH, there were 70 patients with $\mathrm{SCH}$ of non-traumatic origin. The statistics presented here are out of 22,774 patients. All patients had the first episode of NTSH. The incidence rate of NTSH in this study was 3.07 per 1000 patients attending OPD.

Mean age of the patients was 66.26 years $( \pm 15.8)$ with an age range of $10-90$ years. There were 39 male $(55.7 \%)$ and 31 female (44.3\%) patients, ie, the man to women ratio was $1.26(95 \% \mathrm{CI})$. The difference in incidence rate between men to women was statistically not significant ( $p>0.05$ at Pearson chi-square 6.33). The gender wise distribution of conditions associated with NTSH is shown in Table 1 . The analysis did not show preponderance to any condition $(\mathrm{P}=0.39)$. Right eye was affected in 37 patients $(54.3 \%)$, left eye in 28 patients ( $40 \%$ ), and both eyes in 5 patients $(5.7 \%)$. The distribution of associated conditions in NTSH is depicted in Table 2. No etiological factor was detected in 24 patients $(34.3 \%)$. Conjunctivochalasis $(\mathrm{CCH})$ was associated with 15 patients (21.4\%) (Figure 2). An antiplatelet agent was associated with 7 patients (10\%). Hypertension, leukemia, and anemia were associated with 6 patients (8.6\%). Distribution of NTSH-associated conditions according to age is shown in Table 3. NTSH associated with hypertension, diabetes and antiplatelet agents was seen in patients above 41 years of age. The most common site of presentation was nasal side $(\mathrm{n}=36,51.4 \%)$. Fourteen $(20 \%)$ patients had overall involvement of subconjunctiva. Out of these 14 eyes, 5 eyes were associated with leukemia and anemia each and 3 with lymphoma. Clearance of SCH took

Table I Genderwise Distribution of Conditions Associated with NTSC $(\mathrm{P}=0.38)$

\begin{tabular}{|l|l|l|}
\hline Associated Conditions & Male (\%) & Female (\%) \\
\hline Conjuctivochalasis & $8(20.5 \%)$ & $7(22.6 \%)$ \\
Anemia & $2(6.1)$ & $4(10.8)$ \\
Antiplatelet agents & $2(5.4)$ & $5(15.2)$ \\
Diabetes & $\mathrm{I}(2.7)$ & $\mathrm{I}(3)$ \\
Hypertension & $4(10.8)$ & $2(6.1)$ \\
Idiopathic & $15(38.5)$ & $9(29)$ \\
Leukemia & $5(15.2)$ & $\mathrm{I}(2.7)$ \\
Lymphoma & $2(5.4)$ & $2(6.1)$ \\
Total & 39 & $3 \mathrm{I}$ \\
\hline
\end{tabular}


Table 2 Common Etiological Factors Associated with NonTraumatic Subconjunctival Hemorrhage (NTSH)

\begin{tabular}{|l|l|}
\hline Associated Conditions in NTSC & Number of Patients (\%) \\
\hline Conjunctivochalasis & $15(21.4)$ \\
Idiopathic & $24(34.3)$ \\
Antiplatelet agents & $7(10)$ \\
Hypertension & $6(8.6)$ \\
Leukemia & $6(8.6)$ \\
Anemia & $6(8.6)$ \\
Lymphoma & $4(5.7)$ \\
Diabetes & $2(2.9)$ \\
Total & $70(100)$ \\
\hline
\end{tabular}

7-21 days (Figure 3A and $\mathrm{B}$ ). The quadrant-wise distribution of $\mathrm{SCH}$ is shown in Figure 4.

\section{Discussion}

$\mathrm{SCH}$ is a benign condition and does not cause any visual problem. However, it can be a sign of a potentially serious systemic disorder. Although it is a common condition, there are only a few studies about it. In this study, we have observed a proportion of patients presenting to the OPD with associated systemic conditions and the common site of involvement of conjunctival area. Trauma is the common cause of $\mathrm{SCH}^{2,3}$ Inclusion of trauma would not have given an accurate proportion of patients presenting with NTSH. Therefore, trauma was excluded from the criteria for NTSH.

In this OPD-based study of NTSH in the rural population, the proportion of patients attending the ophthalmology department was 3.07 per 1000 patients during the year

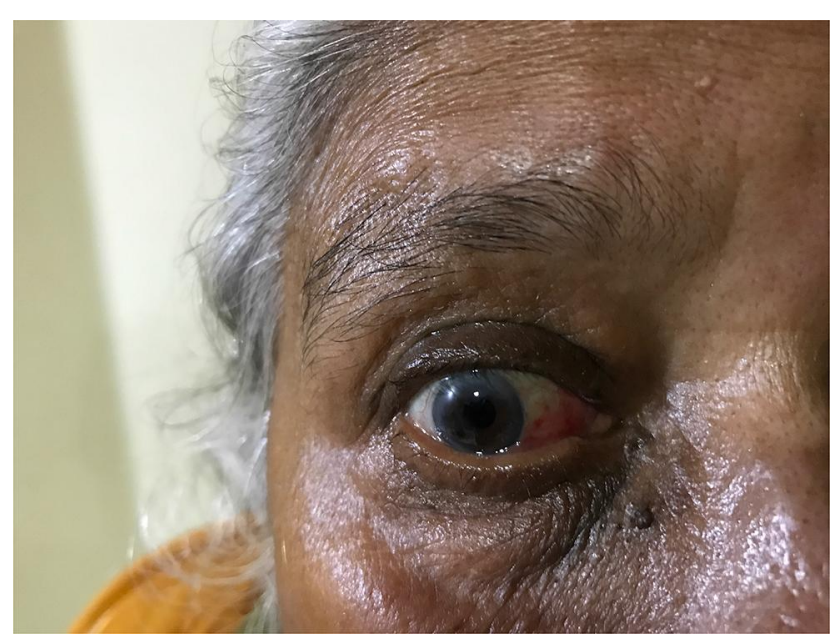

Figure 2 Showing Conjunctivochalasis of the lower lid with subconjunctival hemorrhage.
Table 3 Agewise Distribution of Associated Conditions

\begin{tabular}{|l|l|l|l|l|}
\hline $\begin{array}{l}\text { Associated Conditions } \\
\text { and Age (Years) }\end{array}$ & $10-30$ & $\mathbf{3 I - 4 0}$ & $\mathbf{4 I - 6 0}$ & $\begin{array}{l}\mathbf{6 I} \text { and } \\
\text { Above }\end{array}$ \\
\hline Conjunctivochalasis & - & - & 3 & 3 \\
Anemia & - & - & 3 & 4 \\
Anti-platelet & - & - & - & 2 \\
Diabetes & - & - & - & 6 \\
Hypertension & 1 & 1 & 10 & 12 \\
Idiopathic & 1 & 1 & - & 4 \\
Leukemia & - & - & 2 & 2 \\
Lymphoma & - &
\end{tabular}

2016. Since the incidence rate of NTSH has not been reported from other parts of the country, our data cannot be compared. Hu et al has calculated the incidence rate of NTSH as 65 per 10,000 people per year in the Taiwanese population. The incidence rate was stable during their 12year study period. ${ }^{1}$ Our study was prospective in nature, so follow-up of patients for a long duration was not possible. Thus, we considered one-year duration for the study period. In a retrospective analysis of $\mathrm{SCH}$, Sahinoglu et al reported $32 \%(16 / 50)$ of cases as having NTSH. But they considered traumatic causes in the total sample studied. ${ }^{4}$

The incidence of NTSH was the lowest in the age group of 10-40 years. After 40 years of age, the incidence of NTSH gradually increased due to the increase in the occurrence of various disorders like hypertension, diabetes, and patients on antiplatelet agents. The highest incidence was found after 60 years of age. This is in accordance with the findings of NTSH by $\mathrm{Hu}$ et al. However, they reported a relatively high incidence of NTSH in the age group of $0-9$ years due to the high occurrence of NTSH in newborns. ${ }^{1}$ Our study was based on OPD, so newborns were seen in the ward on a call basis and never presented in the OPD.

The gender-wise distribution of NTSH has shown no sex preponderance. However, the incidence rate was marginally higher in male $(n=39)$ than the female $(n=31)$ with a men-to-women ratio of $1.26(95 \% \mathrm{CI})$. This is in contrast to the study by $\mathrm{Hu}$ et $\mathrm{al}^{1}$ and Kaimbo, ${ }^{5}$ who have shown NTSH is more common in women than men.

NTSH due to leukemia and hypertension were seen more in men than in women. A study on the Indian population has shown a higher incidence rate of leukemia in men than in women. ${ }^{6}$ Contrary to our study, Hu et al found a higher incidence rate of NTSH in females due to the occurrence of few conditions present only in women 


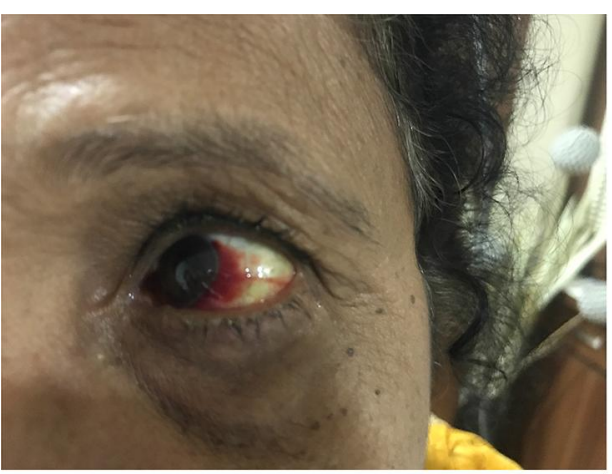

A

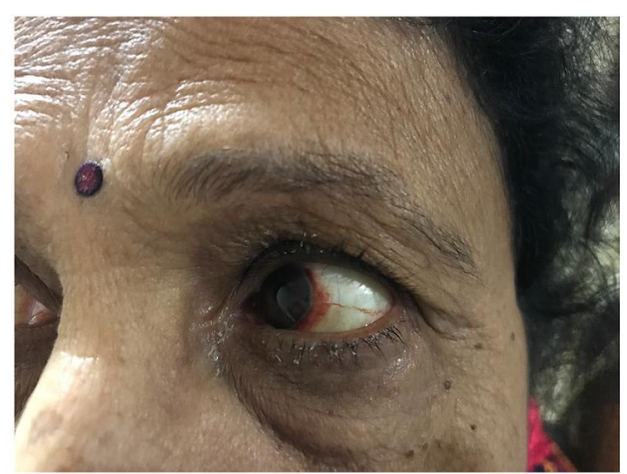

B

Figure 3 (A) Subconjunctival hemorrhage at Day I. (B) Showing Subconjunctival hemorrhage at Day I4 in the absorption stage.

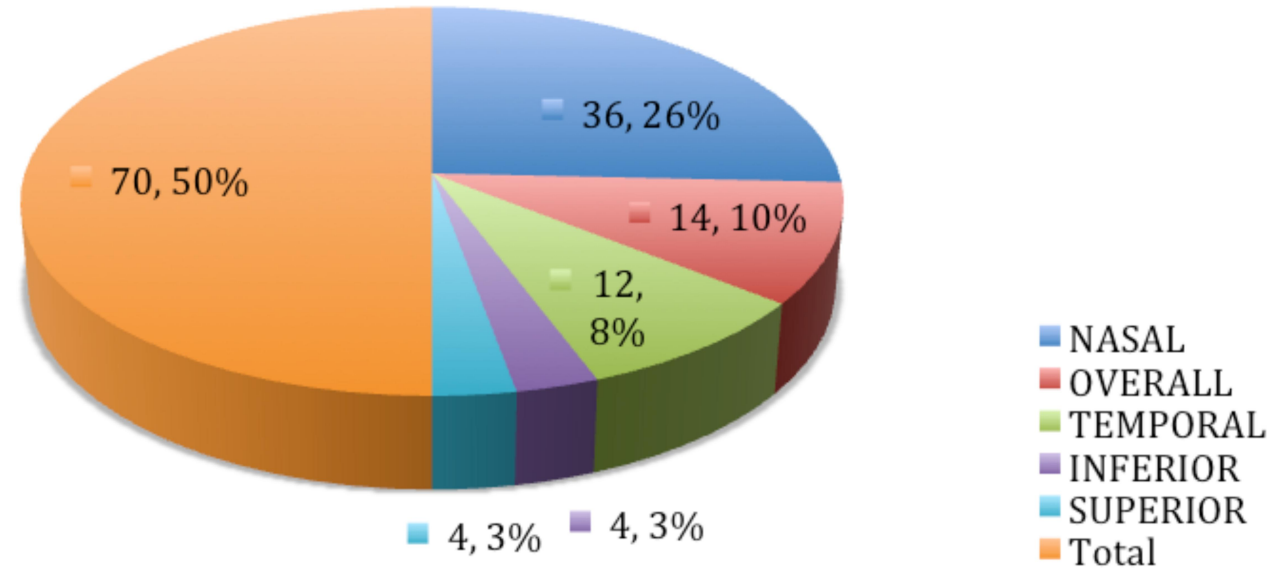

Figure 4 Pie chart showing frequency of non-traumatic subconjunctival according the site of presentation. Nasal quadrant of conjunctiva was affected in $36.26 \%$ cases.

like postpartum hemorrhages or conditions prevalent in women like idiopathic thrombocytopenic purpura. ${ }^{1}$

NTSH due to hypertension was seen more in men than women and could be due to the stressful working environment. This factor could be variable from population to population and needs to be investigated in different areas. Women (15.2\%) on antiplatelet agents had a higher incidence rate of NTSH than men (5.4\%). We could not compare our results, as there are no studies suggesting women on antiplatelet agents have a higher incidence of SCH. Other etiological factors like diabetes and lymphoma were equally distributed in both the genders.

Conjunctivochalasis $(\mathrm{CCH})$ was seen in 15 patients (21.4\%). It is a common ocular surface condition characterized by presence of conjunctival fold between eyelid margin and the globe. In most of the cases it is asymptomatic. However, it can cause ocular irritation and tear film disturbance. Mimura et al have also shown high incidence of SCH in patients with $\mathrm{CCH}^{7}{ }^{7}$ Chan et al, in their study of histopathological study of 29 cases of $\mathrm{CCH}$, have shown majority of cases $(n=22)$ had normal histopathology of conjunctiva. While four cases had inflammatory changes in conjunctiva. ${ }^{8}$ Rubbing of eyes due to irritation could be the causative factor of $\mathrm{SCH}$ in these cases.

NTSH could be the first clinical sign of systemic diseases. Long-term follow-up of patients having $\mathrm{SCH}$ is essential. In a follow-up study of patients having $\mathrm{SCH}$, Wang et al reported a significant risk of developing cerebro vascular episode. ${ }^{9}$ Repeated $\mathrm{SCH}$ may be a sign of multiple myeloma with amyloidosis. ${ }^{10}$

Among the causes listed, NTSH due to hypertension and antiplatelet agents were found to be commonly associated.

We could not find any cause for NTSH in 24 (34.3\%) patients in spite of conducting a thorough investigation. Sahinoglu et al and Kaimbo also could not determine the causative factors in $50 \%$ and $64.3 \%$ of cases of NTSH, respectively. ${ }^{4,5}$

Another common etiological factor listed for the occurrence of NTSH was in patients on antiplatelet agents $(n=7$, 
$10 \%$ ). Various antiplatelet agents used in patients having ischemic heart diseases or having a tendency for thrombosis are aspirin, clopidogrel, and warfarin. These agents have been stated to cause NTSH. ${ }^{3}$ The use of aspirin has been significantly associated with NTSH. ${ }^{1}$ We could not find any association between the duration of use of antiplatelets and the occurrence of SCH. This needs to be investigated in a large cohort study. The appearance of $\mathrm{SCH}$ in these patients may be an indication to consult their physician for dose adjustment of antiplatelet agents.

Anemia was another systemic factor associated with $\mathrm{SCH}$. Nearly three-quarters of the Indian population live in rural areas, and anemia is a major public health problem. In a study on anemia in the rural population of India, Alvarez et al has shown anemia to be prevalent in women and older adults. ${ }^{11}$ The amount of hemoglobin in the blood and the type of anemia leading to $\mathrm{SCH}$ was out of the scope of the present study.

Hypertension has been linked to the occurrence of SCH in various studies. ${ }^{1,4,12}$ Therefore, it is mandatory to check the blood pressure in patients presenting with $\mathrm{SCH}$. Our study also showed a significant association between hypertension and $\mathrm{SCH}$. It may be the cause of repeated hemorrhage. Blood pressure may be normal in patients presenting with $\mathrm{SCH}$ having hypertension controlled on antihypertensive at presentation. The fragility of conjunctival vessels and their rupture may lead to hemorrhage in the conjunctival space. ${ }^{3,13}$

Diabetes is another systemic factor associated with NTSH. ${ }^{2,3}$ However, our study states that it is not a significant factor for NTSH. A similar finding was endorsed by $\mathrm{Hu}$ et al in a large population-based study. ${ }^{1}$ Micro vascular changes in the conjunctival vessels may be a causative factor in the development of hemorrhage.

In the present study, $\mathrm{SCH}$ was more often seen in the nasal area $(n=36,51.4 \%)$. Preponderance of nasal area for $\mathrm{SCH}$ could be a small area of nasal conjunctiva with crowded conjunctival vessels susceptible to $\mathrm{SCH}$. Sahinoglu et al have reported temporal conjunctiva as a common site for the occurrence of $\mathrm{SCH}$. However, they considered traumatic causes of $\mathrm{SCH}$. The reason stated was the protective effect of nasal area and large bulbar conjunctiva. ${ }^{4}$ Diffuse SCH involving all the quadrants of conjunctiva was seen in 14 eyes (20\%). This was mostly seen in patients having lymphoma, anemia, and leukemia.

There was no preponderance of NTSH in a particular eye. However, the right eye was affected in 37 patients
(54.3\%), left eye in 28 patients (40\%), and both eyes in 5 patients $(5.7 \%)$. This could be just an incidental finding than any particular reason. Sahinoglu et al have shown an equal involvement of both eyes. ${ }^{4}$

The present study was based on a hospital. So, those who did not report to the OPD were not included in the study. Consequently, such patients remained unnoticed. However, redness of eye, even if it is not associated with diminished vision, pain and watering, causes substantial alarm to the patient to seek medical help.

The present study was conducted in a rural population. Hence, we propose further studies in different areas or countries to obtain other variables leading to NTSH.

In conclusion, NTSH occurs in 3 out of 1000 individuals per year in the rural population presenting to the OPD. It occurs more often in men than in women. Its incidence was the lowest in the age group of 10-40 years but increased after 40 years of age. Nasal conjunctiva was commonly involved in NTSH. In $34.3 \%$ of cases, the cause of $\mathrm{SCH}$ could not be detected. $\mathrm{CCH}$ was a common cause of NTSH in our study. Use of antiplatelet agents, hypertension, and blood disorders are associated with the risk of NTSH. Patients on anti-platelet drugs presenting with subconjunctival hemorrhage need referral to the physician for the modification of therapy.

\section{Disclosure}

The authors report no conflicts of interest for this work.

\section{References}

1. Hu DN, Mou CH, Chao SC, et al. Incidence of non-traumatic subconjunctival hemorrhage in a Nationwide Study in Taiwan from 2000 to 2011. PLoS One. 2015;10:e132762. doi:10.1371/journal. pone. 0132762

2. Tarlan B, Kiratli H. Subconjunctival hemorrhage: risk factors and potential indicators. Clin Ophthalmol. 2013;7:1163-1170.

3. Mimura T, Usui T, Yamagami S, et al. Recent causes of subconjunctival hemorrhage. Ophthalmologica. 2010;224:133-137. doi:10.1159/ 000236038

4. Sahinoglu-Keskek N, Cevher S, Ergin A. Analysis of subconjunctival hemorrhage. Pak J Med Sci. 2013;29:132-134.

5. Kaimbo WA, Kaimbo D. Epidemiology of traumatic and spontaneous subconjunctival haemorrhages in Congo. Bull Soc Belge Ophtalmol. 2009:31-36.

6. Modak H, Kulkarni SS, Kadakol GS, et al. Prevalence and risk of leukemia in the multi-ethnic population of North Karnataka. Asian Pac $J$ Cancer Prev. 2011;12:671-675.

7. Mimura T, Usui T, Yamagami S, et al. Subconjunctival hemorrhage and conjunctivochalasis. Ophthalmology. 2009;116:1880-1886. doi:10.1016/j.ophtha.2009.03.021

8. Chan DG, Francis IC, Filipic M, Coroneo MT, Yong J. Clinicopathologic study of conjunctivochalasis. Cornea. 2005;24:634. 
9. Wang TJ, Keller JJ, Sheu JJ, Lin HC. A 3-year follow up study on the risk of stroke among patients with conjunctival hemorrhage. Acta Ophthalmol. 2013;91:226-230. doi:10.1111/j.1755-3768.2011.02359.x

10. Felipe AF, Nottage JM, Rapuano CJ. Recurrent bilateral subconjunctival hemorrhage as an initial presentation of multiple myeloma. Oman J Ophthalmol. 2012;5:133-134. doi:10.4103/0974-620X.99384

11. Alvarez-Uria G, Naik PK, Midde M, Yalla PS, Pakam R. Prevalence and severity of anaemia stratified by age and gender in rural India. Anemia. 2014:176182.
12. Fukuyama J, Hayasaka S, Yamada K, Setogawa T. Causes of subconjunctival hemorrhage. Ophthalmologica. 1990;200:63-67. doi: $10.1159 / 000310079$

13. Kittisupamongkol W. Blood pressure in subconjunctival hemorrhage. Ophthalmologica. 2010;224:332. doi:10.1159/000313835

\section{Publish your work in this journal}

Clinical Ophthalmology is an international, peer-reviewed journal covering all subspecialties within ophthalmology. Key topics include: Optometry; Visual science; Pharmacology and drug therapy in eye diseases; Basic Sciences; Primary and Secondary eye care; Patient Safety and Quality of Care Improvements. This journal is indexed on PubMed

Submit your manuscript here: https://www.dovepress.com/clinical-ophthalmology-journal
Central and CAS, and is the official journal of The Society of Clinical Ophthalmology (SCO). The manuscript management system is completely online and includes a very quick and fair peer-review system, which is all easy to use. Visit http://www.dovepress.com/ testimonials.php to read real quotes from published authors. 